\title{
Medication use among pregnant women at a secondary health institution: utilisation patterns and predictors of quantity
}

\author{
Stella T Obadeji ${ }^{1}$, Adetunji Obadeji ${ }^{2}$, Janet O Bamidele ${ }^{3}$, Felix T Ajayi ${ }^{4}$
}

1. Department of Pharmacy State Hospital, Ijaye, Abeokuta, Ogun State, Nigeria.

2. Department of Psychiatry/Pharmacology, College of Medicine, Ekiti State University, Ado-Ekiti, Ekiti State, Nigeria.

3. Department of community medicine and Primary care, Olabisi Onabanjo University Teaching Hospital, Sagamu, Ogun state.

4. Department of Pharmacy, Federal Medical Centre, Ijaye, Abeokuta, Ogun State, Nigeria.

\section{Emails:}

Stella Tolulope Obadeji : toluoba2@gmail.com; Adetunji Obadeji: doctunjioba@yahoo.com; Janet Olufisayo Bamidele: fisayobamidele7@gmail.com; Felix Taiwo Ajayi: felixajayi59@yahoo.com

\begin{abstract}
Background: Despite the lack of adequate studies on the safety of drugs in pregnancy, surprisingly, available evidence shows that pregnant women still take large number of drugs.

Objectives: The study aim was to determine drug utilization pattern and predictors of number of medications used by pregnant women.

Methods: This was a cross-sectional survey of 369 pregnant women attending a secondary health facility. Data were collected using interviewer-administered questionnaire. Descriptive and inferential statistics using the Chi-Square test were carried out with level of significance set at $\mathrm{p}<0.05$.

Results: Three hundred and sixty-nine women were interviewed. Their mean age was 27.7 years $(\mathrm{SD} \pm 4.78)$ and the mean number of pregnancies was 2.46 ( $\mathrm{SD} \pm 1.34$ ). On average, 2.62 medications were taken, with the lowest being 1 and the highest being 12 different medications during the course of pregnancy. Those who were on more than 2 medications were more likely to be older than 30 years, had lower education and with history of associated medical conditions. All participants were on one form of supplements or the other, nearly half had used antimalarials, $12.8 \%, 5.8 \% 2.4 \%$ were on antibiotics, anti-hypertensive and anti-retroviral medications respectively. All the medications prescribed were from category A, B, C, N, and none from category $\mathrm{D}$ and $\mathrm{X}$.

Conclusion: Varieties of medications were used during the course of pregnancy among this population, however, most of these drugs were still within safety profile.

Keywords: medications; pregnancy; pattern; predictors; co-morbidity.

DOI: https://dx.doi.org/10.4314/ahs.v20i3.24

Cite as: Obadeji ST, Obadeji A, Bamidele JO, Ajayi FT. Medication use among pregnant women at a secondary health institution: utilisation patterns and predictors of quantity. Afri Health Sci. 2020;20(3): 1206-1216. bttps://dx.doi.org/10.4314/abs. v20i3.24
\end{abstract}

\section{Corresponding author: \\ Adetunji Obadeji, Department of Psychiatry, \\ Ekiti State University/ Ekiti State University \\ Teaching Hospital, PMB 5535, Ado-Ekiti, Ekiti State, Nigeria. \\ Phone: +2347038733020 \\ E-mail:doctunjioba@yahoo.com}

\section{Introduction}

Although pregnancy is a normal physiological process, oftentimes, it is associated with pathological processes that necessitate the use of one medication or the other. Besides, drugs in the form of nutritional supplement may be needed to complement pregnant women's diet. Drug treatment, however, presents a special concern because the physiology of pregnancy affects the pharmacokinetics of medications used in pregnancy, and some medications, on the other hand, could cause harm 
to the foetus due to the potential teratogenicity. ${ }^{1,2}$ Medications such as folic acid, vitamins, iron, and others may be needed to supplement mothers' diet or to manage co-morbid illness such as diabetes mellitus, malaria, urinary tract infection, hypertension, Human Immune-deficiency Virus (HIV) infection, or mental illness.,

Rational medications use during pregnancy has always created a challenge in antenatal care due to the potential risk associated with use, both to the mother and the foetus. ${ }^{5}$ Drug utilization studies have revealed that a high proportion of women use medications during pregnancy. It has been estimated that between $44 \%$ to $99 \%$ use one form of medication or the other during pregnancy. ${ }^{6,7,8}$ Pregnant women take varieties of medications, ranging from prescribed medications to over the counter (OTC) medications to self-medicate various symptoms of pregnancy such as back pain, headache, heartburn, nausea, vomiting, and haemorrhoids. ${ }^{9} 10$

Several studies have looked at drug use pattern during pregnancy in different parts of the globe. ${ }^{6,7,8,11}$. A study conducted among pregnant women in Ethiopia showed that over $55 \%$ of women had used at least one prescription and over $52 \%$ had used OTC medications during pregnancy. ${ }^{11}$ The use of OTC medications was reported to be higher among urban women in the first trimester and those from the high-income group. ${ }^{12}$ Drugs such as iron and vitamins supplementation are the most frequently used drugs followed by analgesics, tocolytic agents and drugs for chronic conditions and common pregnancy symptoms. ${ }^{13,14,15}$ Another study found that a significant proportion of pregnant women were also on antibiotics and analgesics, with a significant number of medications prescribed from category D and X. $.^{11,16} \mathrm{Be}-$ sides, herbal medications like, ginger and raspberry leaf and cannabis were also reported to be taken in pregnancy, ${ }^{11,16,17,18}$ and self-medication was reported to be common among pregnant women. ${ }^{19}$ Rational drug use in pregnancy, however, requires balancing the benefits and potential risks both to the baby and the mother. This study looked at the pattern of medications and predictors of numbers of medications used in pregnancy.

\section{Methods}

\section{Study design and setting}

This cross-sectional study was carried out at the Obstetrics outpatient department of the General Hospital, Abeokuta over a three-month period (from April 2016 to June 2016). All pregnant women who attended the antenatal clinic during the study period were included.

\section{Study population}

The study population consisted of all women who came for antenatal care during the study period. A total of three hundred and sixty-nine pregnant women participated in the study. These were recruited through a convenient survey, incorporating all consecutive consenting pregnant women attending antenatal care during the course of the study.

\section{Procedure}

After obtaining verbal and written informed consent from the participants, the data were collected using a pre-designed structured questionnaire incorporating basic socio-demographic details such as age, education, occupation, parity, use of herbal products, maternal chronic diseases, medications used, and history of associated medical condition during current pregnancy were enquired from the patients and from information recorded in their case note.

Information regarding their knowledge on the safety of use of medications during pregnancy was also obtained along with the history of self-medication and the use of OTC drugs during pregnancy. Data on prescription drugs were retrieved from their case notes. From the data collected, the drugs were further classified into category A, B, C, D and X based on Food and Drug Administration (FDA) of the United State of America categorization. ${ }^{20}$ Category A refers to drugs in which adequate and well-controlled studies have failed to show any risk to the fetus. Category B on the other hand, refers to drugs in which animal studies have failed to demonstrate a risk to the foetus and there are no adequate and well-controlled studies in pregnant women. Category $\mathrm{C}$ refers to drugs in which animal studies have shown an adverse effect on the foetus but there are no adequate and well-controlled studies in humans, however, potential benefits of such drugs may necessitate use in pregnant women despite potential risks, and those drugs that are yet to be classified into any FDA categories in pregnancy were categorised as $\mathrm{N}$.

\section{Ethical considerations}

Prior to the commencement of the study, ethical clearance was obtained from the Research and Ethics Committee of the Hospital. Written informed consent was sort and obtained from all participants before the questionnaire was administered. 


\section{Statistical analysis}

Statistical analyses were done using the statistical package for social sciences version 19 (SPSS Chicago Inc.) Descriptive statistic was performed to determine the distribution of characteristics of all the variables studied. The number of medication taken during the course of pregnancy was categorized into two: those taken 2 or less and those who took more than two medications bearing in mind that most patients will take haematinics and possibly antimalarials. Chi-square tests with Yates correction were used to describe the relationship between the respondent's characteristics and the number of medication taken. The level of significance was set at $\mathrm{P}<0.05$.

\section{Results}

\section{Subjects' characteristics}

Three hundred and sixty-nine women were inter- viewed. The age of the participants ranges from 16 to 43 years with a mean of 27.7years Standard Deviation $(\mathrm{SD})=4.78$. The number of gravidity ranges from 1 to 7 with a mean of $2.46(\mathrm{SD}=1.337)$. On the average 2.62 medications were taken, with the lowest being 1 while the highest was 12 during current pregnancy.

\section{Socio-demographics variables}

Majority of the participants $(48.8 \%)$ were within the age group 30-39, $178(47.7 \%)$ were in the age group 2029 , while $1.1 \%$ were under 20 years. Most were married $(88.3 \%)$, while $1.1 \%$ of the participants were separated. Two hundred and seventy-four $(74.3 \%)$ were employed while the remaining were not. Other socio-demographics are as shown in table 1.

Table 1: Socio-demographic variables of the participants

\begin{tabular}{lc}
\hline Variables & Frequencies n (\%) \\
\hline Age groups & \\
$<20$ & $4(1.1)$ \\
$20-29$ & $178(47.7)$ \\
$30-39$ & $180(48.8)$ \\
$\geq 40$ & $9(2.4)$ \\
Marital status & $39(10.6)$ \\
Single & $326(88.3)$ \\
Married & $4(1.1)$ \\
Separated & \\
Employment Status & $274(74.3)$ \\
Employed & $95(25.7)$ \\
Unemployed & $10(2.7)$ \\
Level of Education & $41(11.1)$ \\
None & $133(36.0)$ \\
Primary & $185(50.2)$ \\
Secondary & \\
Tertiary & $108(29.3)$ \\
Parity & $229(62.0)$ \\
Primigravida & $32(8.7)$ \\
Multigravida & \\
Grand-multigravida & $244(66.1)$ \\
Pregnancy status & $125(33.9)$ \\
Planned & \\
Unplanned & $248(67.2)$ \\
Religion & $121(32.8)$ \\
Christianity & \\
Islam & \\
\hline &
\end{tabular}


The pattern of anti-malarial and other anti-infective medications used in pregnancy

The pattern of anti-malarial and other anti-infective medications use in pregnancy are as shown in table 2. Sulfadoxine/pyrimethamine (such as Fansidar) was the commonest anti-malaria used by $43.4 \%$ of pregnant women. This was followed by Artemisinin Combination Therapy (ACTs) $(13.0 \%)$, Chloroquine $(1.4 \%)$ and others as shown in table 2 . Twenty three $(6.2 \%)$ of pregnant women had used penicillins (such as amoxicillin and ampicillin-cloxacillin) and 18 (4.9\%) had used cephalosporin. Other anti-infective agents used by the participants are as shown in table 2 .

Table 2: Pattern of anti-malarial medications used in pregnancy

\begin{tabular}{lll}
\hline \multicolumn{1}{c}{ Medications } & FDA Classifications & Frequencies (\%) \\
\hline Anti-malarias & $\mathrm{C}$ & $160(43.4)$ \\
Sulfadoxine/pyrimethamine & $\mathrm{C}$ & $48(13.0)$ \\
ACTs & $\mathrm{N}$ & $5(1.4)$ \\
Cloroquine & $\mathrm{C}$ & $3(0.8)$ \\
Proguanil & $\mathrm{C}$ & $2(0.6)$ \\
Quinine & & \\
Antibiotics & $\mathrm{B}$ & $23(6.2)$ \\
Penicillins & $\mathrm{B}$ & $18(4.9)$ \\
Cephallosporins & $\mathrm{C}$ & $4(1.1)$ \\
Sulphonamides & $\mathrm{B}$ & $2(0.6)$ \\
Nitrofurantoins & $\mathrm{B}$ & $11(3.0)$ \\
Ethromycins & $\mathrm{B}$ & $11(3.0)$ \\
Metronidazole & &
\end{tabular}

Pattern of hematinics and analgesics used in pregnancy

All the pregnant women were giving one form of hematinic or the other. One hundred and fifty (49.7\%) were given preparations containing various vitamins and minerals, 197 (53.4\%) were given a combination of iron, folic acid, and vitamin B complex, 22 (6.0\%) were given folic acid alone, while $26(7.1 \%)$ were given additional calcium supplement.

Alongside these, an appreciable number had taken analgesic, largely, paracetamol (34.4\%) and non-steroidal anti-inflammatory drugs (NSAIDs) (mainly aspirin and diclofenac sodium) by $17(4.6 \%)$ of the the pregnant women. Other analgesics used are as shown in table 3. 
Table 3: Pattern of hematinics and analgesics used in pregnancy

\begin{tabular}{lcc}
\hline Medications & FDA & Frequencies (\%) \\
\hline Hematinics & A & $347(94.0 \%)$ \\
Folic acid alone & A & $22(6.0)$ \\
Calcium & A & $26(7.1)$ \\
Analgesics & & \\
Paracetamol & B & $127(34.4)$ \\
NSAIDs & C & $17(4.6)$ \\
Tramadol & C & $2(0.5)$ \\
Pentazocine & C & $1(0.3)$ \\
\hline
\end{tabular}

Pattern of Anti-retro-viral medications

As shown in table 4 , nine (2.4\%) of the participants were on lamivudine, $3(0.8 \%)$ were on zidovudine, $3(0.8 \%)$ on Nevirapine while $6(1.6 \%)$ were on levaviren.

Table 4: Pattern of Anti-HIV medications used in pregnancy

\begin{tabular}{lcc}
\hline Medications & FDA Class & Frequencies (\%) \\
\hline Anti HIV drugs & $\mathrm{C}$ & $9(2.4)$ \\
Lamivudine & $\mathrm{C}$ & $3(0.8)$ \\
Zidovudine & $\mathrm{B}$ & $3(0.8)$ \\
Nevirapine & $\mathrm{B}$ & $6(1.8)$ \\
Tenovir & $\mathrm{B}$ & $6(1.6)$ \\
Levaviren & & \\
\hline
\end{tabular}

Pattern of anti-hypertensives and other medications

Table 5 shows the pattern of anti-hypertensives and other medications. Nine $(2.5 \%)$ of the pregnant women were using labetalol while 12(3.3\%) were on nifedipine. Sixteen $(4.2 \%)$ had used clotrimazole pessaries, while only $2(0.5 \%)$ had used oral anti-fungal medication. The pattern of other medications is as shown in table 5 . 
Table 5: Anti-hypertensive and other medications

\begin{tabular}{lcc}
\hline \multicolumn{1}{c}{ Medications } & FDA class & Frequencies (\%) \\
\hline Anti-hypertensive & $\mathrm{C}$ & $9(2.5)$ \\
Labetalol & $\mathrm{C}$ & $12(3.3)$ \\
Nifedipine & & \\
Antifungal & $\mathrm{B}$ & $16(4.2)$ \\
Clortrimazole pessaries & $\mathrm{C}$ & $2(0.5)$ \\
Oral antifungal & & \\
Hormonal preparations & $\mathrm{C}$ & $13(3.5)$ \\
Methyl estradiol & & $18(4.9)$ \\
Sedatives Hypnotics & $\mathrm{N}$ & $6(2.5)$ \\
Bromazepam & $\mathrm{N}$ & $3(0.8)$ \\
Diazepam & & $2(0.6)$ \\
Others & $\mathrm{C}$ & \\
Salbutamol & $\mathrm{C}$ & \\
Prednisolone & & \\
\hline
\end{tabular}

\section{Associated medical conditions in pregnancy}

Malaria was the commonest medical condition diagnosed in pregnancy affecting $64(17.3 \%)$ of pregnant women, followed by urinary tract infection (UTI) 27 (7.3\%), hypertension 14 (3.8\%), HIV infection 7 (1.9\%) and others (e.g asthma)

Source and attitude towards prescribed medications

One hundred and seventeen participants (31.7\%) had used medications without prescription during the course of pregnancy Two hundred and seventy $(73.4 \%)$ were aware of the risk of self-medication while $98(26.6 \%)$ were not. Most $(57.5 \%)$ did not find out about side effect of prescribed medication before taking them, however, $147(39.9 \%)$ did ask about side effects while the remaining $10(2.7 \%)$ can't recollect whether they did so or not.

Relationship between demographic variables and number of medications used

As shown in table 6, lower proportion 59 (32.4\%) of those below the age of thirty compared with those aged 30 and above $88(47.1 \%)$ had used more than 2 medications during the course of pregnancy and the difference was statistically significant $(p=0.004)$. Likewise, there was a statistically significant association between the levels of education, the presence of associated medical conditions and the number of medications used ( $p<0.050)$. The relationship between other variables and the number of medications were not statistically significant $(\mathrm{p}>0.05)$. 
Table 6: Socio-demographics variables in relation to the number of medications

\begin{tabular}{|c|c|c|c|}
\hline Variables & $\leq 2$ medications & $>2$ medications & Statistics \\
\hline \multicolumn{4}{|l|}{ Age groups } \\
\hline$<30$ & $123(67.6)$ & $59(32.4)$ & $\mathrm{P}=0.004$ \\
\hline$\geq 30$ & $99(52.9)$ & $88(47.1)$ & \\
\hline \multicolumn{4}{|l|}{ Marital status } \\
\hline Single & $28(71.8)$ & $11(28.2)$ & $\mathrm{p}=0.107$ \\
\hline Married & $193(59.2)$ & $133(40.8)$ & \\
\hline Separated & $1(25.0)$ & $3(75.0)$ & \\
\hline \multicolumn{4}{|l|}{ Employment Status } \\
\hline Employed & $164(60.1)$ & $109(39.9)$ & $\mathrm{p}=0.601$ \\
\hline Unemployed & $57(60.0)$ & $38(40.0)$ & \\
\hline \multicolumn{4}{|l|}{ Level of Education } \\
\hline None & $2(20.0)$ & $8(80.0)$ & $\mathrm{p}=0.014$ \\
\hline Primary & $23(51.6)$ & $18(43.9)$ & \\
\hline Secondary & $90(67.7)$ & $43(32.3)$ & \\
\hline Tertiary & $107(57.8)$ & $78(42.2)$ & \\
\hline \multicolumn{4}{|l|}{ Gravidity } \\
\hline Primigravida & $71(65.7)$ & $37(34.3)$ & $\mathrm{p}=0.232$ \\
\hline Multigravida & $135(59.0)$ & $94(41.0)$ & \\
\hline Grand-multigravida & $16(50.0)$ & $16(50.0)$ & \\
\hline \multicolumn{4}{|c|}{ Trimester } \\
\hline $1^{\mathrm{sT}}$ & $6(50.0)$ & $6(50.0)$ & $\mathrm{p}=0.623$ \\
\hline $2^{\mathrm{ND}}$ & $71(58.2)$ & $51(41.8)$ & \\
\hline $3^{\mathrm{RD}}$ & $145(61.7)$ & $90(38.3)$ & \\
\hline \multicolumn{4}{|c|}{ Associated Medical conditions } \\
\hline Yes & $33(21.1)$ & $104(75.9)$ & $\mathrm{p}=0.000$ \\
\hline No & $189(81.5)$ & $43(18.5)$ & \\
\hline \multicolumn{4}{|c|}{ Use of herbal Medications } \\
\hline Yes & $47(58.0)$ & $34(42.0)$ & $\mathrm{p}=0.198$ \\
\hline No & $175(60.8)$ & $113(39.2)$ & \\
\hline
\end{tabular}

\section{Discussion}

Drugs play an important role in promoting maternal well-being. However, rational drug use during pregnancy needs to be ensured to allow for maternal and foetal wellbeing as well as prevent complication in the foetus. In this study, we looked at the pattern of drug use among a population of pregnant women at a secondary health facility. Majority of the 369 pregnant women that participated in the study were between the ages of 2039 with a mean age of 29.65 . This finding is similar to earlier findings. ${ }^{21,22}$. Interestingly, over $50 \%$ of the pregnant women had tertiary education compared to about $19 \%$ reported by Gwande and colleagues ${ }^{21}$ in 2012 or about $12 \%$ reported in Ethiopia. ${ }^{11}$ In all, over $80 \%$ had secondary education and above suggesting a fairly educated population. Ideally, this is expected to go a long way in enhancing drug education among pregnant women and in aiding rational use of medications in pregnancy. However, this may not be a representation of the general population of women of child bearing age in the country because the finding was based on just one secondary health centre in a relatively more educated region of the country. In a similar study in India, over $80 \%$ of the pregnant women were literate similar to the finding in this study. ${ }^{23}$

On average, about 3 different medications were consumed by each pregnant woman, with the lowest being 1 and the highest being 12 in the course of current pregnancy, considering all form of haematinics/supplement as one. Similarly, Mohammed and his colleagues in 2013 reported an average of approximately two prescription medications and OTC medications were used by each pregnant women excluding supplements. ${ }^{11}$ In this study, all the women interviewed were using one form of haematinic/supplement or the other. The majority were using a combination of iron, folic acid, and other multivitamins either combined together or as different formulations. Only less than 10 percent were on folic acid alone. Globally, pregnant women and young children are at high risk of anaemia with iron deficiency contributing to $50 \%$ of this risk. ${ }^{24}$ Besides, maternal iron-folic acid supplementation reduced mortality and improves childhood survival among children between birth and 7 years. ${ }^{24,25}$ According to the World Health Organisation (WHO), the prevalence of anae- 
mia during pregnancy in developed countries is about $14 \%$ and in developing countries is about $50 \% .^{26,27}$ This may further substantiate the use of haematinics by virtually all pregnant women in this study.

In this study, nearly half of the women had used sulphadoxine-pyrimethamine (SP) at one stage of the pregnancy or the other, while another $13 \%$ had used ACT. In all areas with moderate to high malaria transmission in Africa, the WHO recommends intermittent preventive treatment in pregnancy with sulfadoxine-pyrimethamine (IPTp-SP) ${ }^{28}$ In line with this, the national policy on malaria control recommends use IPTp-SP for chemoprophylaxis against malaria in pregnancy particularly in the second and third trimester of pregnancy, and the use of quinine and ACT for acute treatment of malaria in the first, and second/third trimesters which may explain the observation in this study. ${ }^{29,30,31}$ Only a few percent had used chloroquine, proguanil or quinine in pregnancy. This may be due to high rate of resistance to these medications that have been reported in this environment. ${ }^{29}$ Available information on the safety of anti-malarial drugs in pregnancy from both animal and human studies, shows that antimalarial such as chloroquine, amodiaquine, quinine, azithromycin, SP, mefloquine, dapsone-chlorproguanil, artemisinin derivatives, atovaquone-proguanil, and lumefantrine can be used in pregnancy. ${ }^{30}$

The presence of infections such as urinary tract infection (UTI), HIV and other forms of infections increases the need for antibiotics and other anti-infective agents in pregnancy. Penicillins in the form of ampicillin, amoxicillin or ampicillin-cloxacin combination, followed by cephalosporin in oral or intravenous forms were the commonest antibiotics used by pregnant women in this study. The trend observed in this study is similar to the observation in other studies. ${ }^{32,33}$ Even though these antibiotics are considered to be safe in pregnancy, there is possibility of teratogenicity usually minor malformations which often pass undetected. ${ }^{34}$ This necessitates the need to use these agents with caution, more importantly in the first trimester.

About a third had used paracetamol during the course of pregnancy while about $5 \%$ had used NSAIDS at one time or the other. Compared with other analgesics, paracetamol may have been used by greater proportion because it is relatively safe in pregnancy and for the fact that it is readily available, even without a prescription. In a similar study in India, only about $11 \%$ had used paracetamol and about $4 \%$ had used NSAIDs. In Ethiopia on the other hand, nearly $90 \%$ of the pregnant women had used NSAIDs. ${ }^{35}$ Despite the fact that NSAIDs may have a deleterious effect on the foetus, quite a significant number pregnant women still take these medications in pregnancy. According to research, NSAIDs, such as diclofenac increases the risks of miscarriage and malformations in early pregnancy and in the third trimester, can cause early closure and constriction of ductus arteriosus with subsequent neonatal pulmonary hypertension and transient right-sided hypertrophic cardiomyopathy. ${ }^{36,37}$ Therefore, it is very important to use these more rationally or search for other alternatives that could alleviate pain during pregnancy.

Among the pregnant women studied, about $5 \%$ were on anti-hypertensives, specifically, nifedipine and labetalol. This is either prescribed as a single drug or in combination with others. The restriction to only these two medications may possibly be due to their safety profile in pregnancy compared to others. Studies have shown that hypertension occurs in $5 \%$ to $10 \%$ of pregnancies, yet information on the safety of antihypertensive medication use during pregnancy is limited, thus limiting the scope of anti-hypertensives in pregnancy. ${ }^{38,39}$

Looking at the relationship between demographic variables and the number of medication used, interestingly, patients who were age thirty and above were significantly more likely to have used more than 2 types of medications compared with those who are age 30years or less. Increased rate of complications with increasing age may possibly explain this. A significant association was also observed with the level of education and number of medication used. Education affects the overall quality of life. Patients with no or low education are more likely to be prone to malaria and other infections which may likely require them taking more medications. In this study, no association was found between marital status, employment status, gravidity, though a higher proportion of those with higher number of pregnancy was likely to have taken more medications.

Similarly, a significant relationship was observed between the number of medications and clinical variables such as the presence of associated medical diagnoses and usage of more than 2 medications. This was not unexpected, as the presence of associated medical conditions necessitates additional medications apart from the haematinics, thus increasing the number of medication taking by such patients.

A substantial proportion of the women studied (31.7\%) still use the medication without a prescription in pregnancy. Women of childbearing age should be well in- 
formed of the risks associated with the use of OTC drugs. This has been reported as a common occurrence among the illiterates than among literate ones, and among those in the lower economic class than among those in the higher class. ${ }^{23}$ Affordability of cost of care may be an important factor, and providing affordable options or ensuring availability of health insurance for pregnant women may go a long way in reducing such. In a study from the USA, OTC medications (e.g., ibuprofen) that are contraindicated in pregnancy were used at unexpectedly at high rates during pregnancy. ${ }^{40}$ This emphasizes the need to properly educate pregnant women on the danger such poses to their developing foetus.

\section{Conclusion}

In this study, several classes of medications were used, however, all were from category A, B, C and N. There was no drug prescribed from category $\mathrm{D}$ and $\mathrm{X}$, indicating that most of the medications were within safety margin within pregnancy. Increase maternal age, lower level of education as well as the presence of co-morbidity were predictors of usage of higher numbers of classes of medications in pregnancy. Educating women to have their babies at a relatively young age may go long way in reducing the need for a higher number of medications, thus reducing the possibility of untoward effects of these medications on the foetus and their mothers.

\section{Acknowledgments}

The authors would like to express their appreciation to all pregnant women who took part in the study.

\section{Funding}

This research did not receive any grant or funding from any agencies.

\section{Competing interests}

The authors declare that they have no competing interests

\section{References}

1. Sharma R, Kapoor, B, Verma, U. Drug utilization pattern during pregnancy in North India. Ind J Med Sci. 2006; 60(7): 277-87. http://dx.doi.org/10.4103/00195359.26602

2. Nielsen GL, Nørgard B, Puho E, Rothman KJ, Sørensen HT, Czeizel AE. Risk of specific congenital abnormalities in the offspring of women with diabetes. Diabet Med. 2005 June; 22 (6): 693-96. http://dx.doi. org/10.1111/j.1464- 5491.2005.01477.x
3. Sachdeva P, Patel BG, Patel BK. Drug Use in Pregnancy; a Point to Ponder! Indian J Pharm Sci. 2009; 71(1):1-7. http://dx.doi.org/10.4103/0250474X.51941

4. Varghese BM, Vanaja K, Banu R. Assessment of Drug Usage Pattern during Pregnancy at a Tertiary Care Teaching Hospital. J. Med. Public Health 2016; 6(3):130-5.

5. Kacew S. Fetal consequences and risks attributed to the use of prescribed and over-the-counter (OTC) preparations during pregnancy. Int J Clin Pharmacol Ther. 1994; 32(7):335-43.

6. Bakker MK, Jentik J, Vroom F. Drug prescription patterns before, during and after pregnancy for chronic, occasional and pregnancy related drugs in the Netherlands. BJOG An International Journal of Obstetrics and Gynaecology 2006; 113: 559-68.

7. Abubakar K., Abdulkadir R., Abubakar S. B., Jimoh A. O., Ugwah-Oguejiofor J. C., Danzaki A. M., Drug Utilization Pattern in Pregnancy in a Tertiary Hospital in Sokoto, North West, Journal of Health Science 2014; 4(4):99-104. doi: 10.5923/j.health.20140404.04.

8. Bedewi N, Sisay M, Edessa D. Drug utilization pattern among pregnant women attending maternal and child health clinic of tertiary hospital in eastern Ethiopia: Consideration of toxicological perspectives. BMC Res Notes, 2018;11(1):858. doi: 10.1186/s13104018-3966-5.

9. Gibson PS, Powrie R, Star J. Herbal and alternative medicine use during pregnancy: a cross-sectional survey. Obstet Gynecol. 2001;97.

10. Vazquez JC. Constipation, haemorrhoids, and heartburn in pregnancy. BMJ Clin Evid. 2010; 3:1411.

11. Mohammed A.Mohammed, Jemal Hussein Ahmed, Abdulhalik workicho, Hisham S. Aljadhey., Medications use among pregnant women in Ethiopia: A cross sectional study. J App Pharm Sci. 2013; 3 (04): 116-123.

12. Shruti G, Sree PK, Rao YV. Drug use pattern of over-the-counter and alternative medications in pregnancy: A cross sectional descriptive study. National Journal of Physiology, Pharmacy and Pharmacology 2015; 5(3): 195.

13. Gadisa DA \& Guyo AW. Drug Prescribing Pattern and Its potential Fetal Harm among Pregnant Women in Bishoftu General Hospital, Oromia Regional State, Ethiopia. European Journal of Pharmaceutical and Medical Research 2014; 1(1): 13-34.

14. Christian P, Stewart CP, LeClerq SC, Wu L, Kaz J, Keith P, et al. Antenatal and postnatal iron supplementation and childhood mortality in rural Nepal: A 
prospective follow-up in a Randomized, Controlled Community Trial. American Journal of Epidemiology 2009; 170 (9):1127-36.

15. Kalaivani K. Prevalence and consequences of anemia in pregnancy. Indian Journal of Medical Research 2009; 130:627-33.

16. Negasa M, Tigabu BM. Drug prescribing pattern among pregnant mothers attending obstetrics and gynecology department in Hiwot Fana Specialized Teaching Hospital, Ethiopia. Arch Pharma Pract 2014; 5:78-83

17. Koren GK, Astuszak AP, Ito S. Drugs in pregnancy. New England Journal of Medicine. 1998; 338(16):1128-37.

18. Bamgboye EA, Amoran OE, Yusuf OB. Self-medication practices among workers in a tertiary hospital in Nigeria. Afr J Med Med Sci. 2006; 35(4):411-5. 19. Abasiubong F, Bassey EA, Udobang JA, Akinbami OS, Udoh SB, Idung AU. Self-Medication: potential risks and hazards among pregnant women in Uyo, Nigeria. Pan Afr Med J. 2012; 13:15.

20. FDA. U.S. Food and Drug Administration. Pregnancy and lactation labeling final rule. December 3, 2014. http://www.fda.gov/Drugs/DevelopmentApprovalProcess/DevelopmentResources/Labeling/ ucm093307.htm. Accessed May 15, 2019.

21. Gawde1SR, Bhide SS, Patel TC, A. R. Chauhan AR, Mayadeo NM and Sawardekar SB (2013). Drug Prescription Pattern in Pregnant Women Attending Antenatal Out Patient Department of a Tertiary Care Hospital. British Journal of Pharmacentical Research 2013; 3(1): 1-12.

22. Asfaw F, Bekele M, Temam S, \& Kelel M. Drug utilization pattern during pregnancy in Nekemte referral hospital: a cross sectional study. International Journal of Scientific Reports 2016; 2(8): 201-206. doi: http://dx. doi.org/10.18203/issn.2454-2156.

23. Inamdar I, Aswar M, Sonkar V, Doibale M. Drug utilization pattern during pregnancy. Indian Med Gazette, 2012; 146:305-311.

24. Christian P, Stewart CP, LeClerq SC, Wu L, Katz J, West KP et al. Antenatal and postnatal iron supplementation and childhood mortality in rural Nepal: a prospective follow-up in a randomized, controlled community trial. Am J Epidemiol. 2009; 170(9):1127-1136. doi:10.1093/aje/kwp253.

25. Devakumar D, Fall CH, Sachdev HS, Margetts BM, Osmond C, Wells JC, Costello A, Osrin D. Maternal antenatal multiple micronutrient supplementation for long-term health benefits in children: a systemat- ic review and meta-analysis. BMC Med. 2016; 16;14:90. doi: 10.1186/s12916-016-0633-3.

26. Kalaivani K. Prevalence and consequences of anaemia in pregnancy. Indian Journal of Medical Research. 2009; 130:627-33.

27. WHO; (2001). World Health Organization. WHO/NUT/MCM/92.2. WHO; Geneva: 1992. The prevalence of anemia in women: A tabulation of available information.

28. WHO (2018). Intermittent preventive treatment in pregnancy (IPTp). Avalable at: https://www. who.int/malaria/areas/preventive_therapies/pregnancy/en/.Last accessed 11 ${ }^{\text {th }}$ of May, 2019.

29. Federal Ministry of Health, National Malaria Control Programme, Abuja, Nigeria. Strategic Plan. 2009-2013. pp. 24-28. Available from: http://nmcpnigeria.org/f/Nigeria Annex 1_National Malaria Control Strategy Plan 2009-2013. Last assessed on May $14^{\text {th }}$ 2019.

30. Nosten F, McGready R, d'Alessandro U, Bonell A, Verhoeff F, Menendez C, Mutabingwa T, Brabin B. Antimalarial drugs in pregnancy: a review. Curr Drug Saf. 2006 Jan;1(1):1-15

31. Ugwu EO, Iferikigwe ES, Obi SN, Ugwu AO, Agu PU, Okezie OA. Anti-malaria prescription in pregnancy among general practitioners in Enugu state, southeast Nigeria. Niger Med J 2013; 54(2):96-9. doi: 10.4103/0300-1652.

32. Babu RH, Basha RM, Kumar BS and Nagaraju R. A Study on Anti-microbial Prescribing Pattern during Pregnancy in a Tertiary care Hospital in South India. International Journal of Innovative Pharmacentical Research, 2010; 1(1): 11-13.

33. Petersen I, Gilbert R, Evans S, Ridolfi A, Nazareth I. Oral antibiotic prescribing during pregnancy in primary care: UK population-based study. Journal of $A n$ timicrobial Chemotherapy, 65(10): 2238-2246.

34. Erić M, Leppée M, Sabo A, Culig J. Beta-lactam antibiotics during pregnancy: a cross-sectional comparative study Zagreb-Novi Sad. Eur Rev Med Pharmacol Sci. 2012; 16(1):103-10.

35. Kassaw C, Wabe NT. Pregnant women and non-steroidal anti-inflammatory drugs: knowledge, perception and drug consumption pattern during pregnancy in Ethiopia. N Am J Med Sci. 2012; 4(2):72-6. doi: 10.4103/1947-2714.93377.

36. Siu KL \& Lee W.H. Maternal diclofenac sodium ingestion and severe neonatal pulmonary hypertension. J. Paediatr. Child Health, 2004: 40: 152-153.

37. Antonucci R, Zaffanello M, Puxeddu E, Por- 
cella A, Cuzzolin L, Pilloni MD, Fanos V. (2012). 39. Firas A Ghanem \& Assad Movahed. Use of Use of Non-steroidal Anti-inflammatory Drugs in Antihypertensive Drugs during Pregnancy and LactaPregnancy: Impact on the Fetus and Newborn. Cur- tion. Cardiovascular Therapeutics, 2008; 26(1): 38-4 9.

rent Drug Metabolism, 2012; 13: 474-90 PubMed . 40. Glover DD, Amonkar M. Rybeck BF, Tracy TS. $10.2174 / 138920012800166607$.

Prescription, over-the-counter, and herbal medicine

38. Sibai BM. Chronic hypertension in pregnancy. use in a rural, obstetric population. Am J Obstet Gynecol Obstet Gynecol. 2002; 100(2): 369-77. 2003;188:1039-45 PubMed . https://doi.org/10.1067/ mob.2003.223 